\title{
SISTEM PRODUKSI DAN PENGOLAHAN KOPI BERKELANJUTAN: STATE OF THE ART
}

Sustainable Production and Processing System of Coffee: State of the Art

\author{
Rachman Jaya $^{1) *}$, Yusriana Yusriana ${ }^{2)}$, Rizki Ardiansyah ${ }^{1)}$ \\ ${ }^{1)}$ Balai Pengkajian Teknologi Pertanian Aceh \\ Jl. Panglima Nyak Makam No. 27 Lampineung Banda Aceh, Indonesia, 23125 \\ ${ }^{2)}$ Program Studi Teknologi Hasil Pertanian, Fakultas Pertanian, Universitas Syiah Kuala, \\ Banda Aceh, Indonesia \\ *Korespondensi Penulis: jaya.rachman@yahoo.co.id
}

\begin{abstract}
Last 10 years, more than 50 papers and handbooks have been published on the topic of sustainable production and processing in the coffee commodity. Review process is used by desk study based on several scientific journals which are related to the topic. It was found by scientific publisher webs such as Scopus, Ebsco, Academia.edu, Researchgate, Portal Garuda, DOAJ and Google Scholar. Technically, sustainability was discussed at least 3 aspects, i.e. economic, social and ecology. In global growth, particularly a coffee commodity has been disturbing production which was caused by global warming, fair-trade and social conflict. On the other hand, dynamically there has been increasing of demand (export and local) due to lifestyle. Based on the fact, the realistic solution is needed on these matters. This study has done several articles reviewed and synthesized. The systematic of it's through content analysis on that article and then clustered by a topic which assessed. The realistic solution complied based on economic, social and ecology aspects in a sustainable production and processing. Finally, we suggest several new techniques and products (downstream) which could be developed to reach the sustainability and processing of the coffee, especially cold-brew for new coffee product.
\end{abstract}

Keywords: coffee, processing, state of the art, sustainable production

\section{PENDAHULUAN}

Saat ini kopi telah menjadi gaya hidup (social life style) di kota-kota besar dunia (Cowan, 2005) tidak hanya di kalangan kaula muda, tetapi juga pada kalangan dewasa. Pada sisi yang lain, globalisasi menuntut sistem produksi dan proses pengolahan serta bisnis yang berkelanjutan melalui sertifikasi (Giovannucci dan Ponte, 2005; Astuti et al., 2015). Makna berkelanjutan setidaknya menyangkut aspek ekonomi, sosial dan lingkungan (Adam dan Ghaly, 2007; Nuva et al., 2013; Jaya et al., 2013; Narita dan Inouye, 2014; Krishnan, 2017; Rosen, 2018), termasuk juga masalah perubahan iklim global (Syakir dan Surmaini, 2017; Ram, 2018) pada komoditas kopi (Cremaschi et al., 2018), termasuk di Indonesia (Wijaya et al., 2017).

Secara teknis, total produksi kopi dunia mengalami dinamika yang cukup tajam, baik dari jenis arabika maupun robusta (Gambar 1). Peningkatan produksi salah satunya dipasok oleh Vietnam yang mencapai 19\% (Ho et al., 2018), yang telah menjadi salah satu eksportir utama kopi dunia, selain Brazil, Ethiophia, Indonesia dan Kolombia (ICO, 2019; Volsi et al., 2019), sedangkan produk kopi Indonesia mencapai 565,08 ton pada tahun 2018 atau $5.53 \%$ dari total produksi kopi dunia (ICO, 2019). 


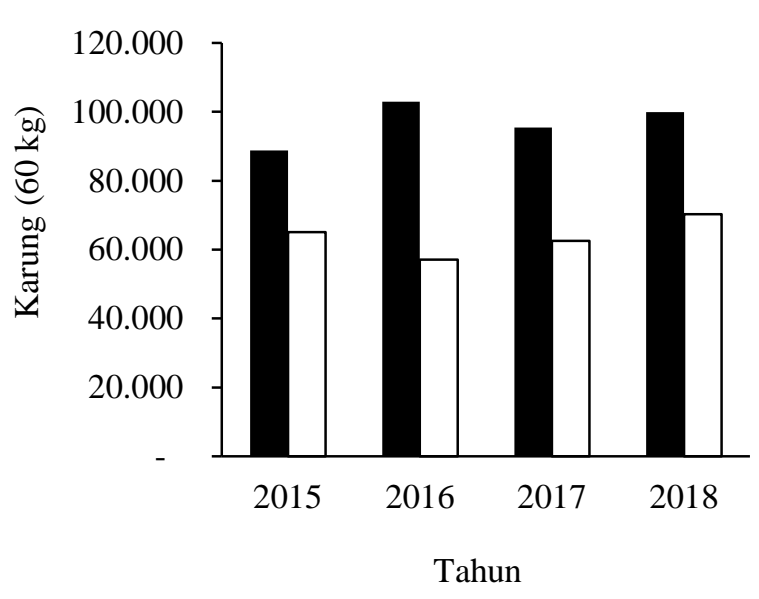

Gambar 1. Tren produksi kopi arabika (ם) dan robusta $(\square)$ dunia pada 4 tahun terakhir (Sumber: ICO, 2019)

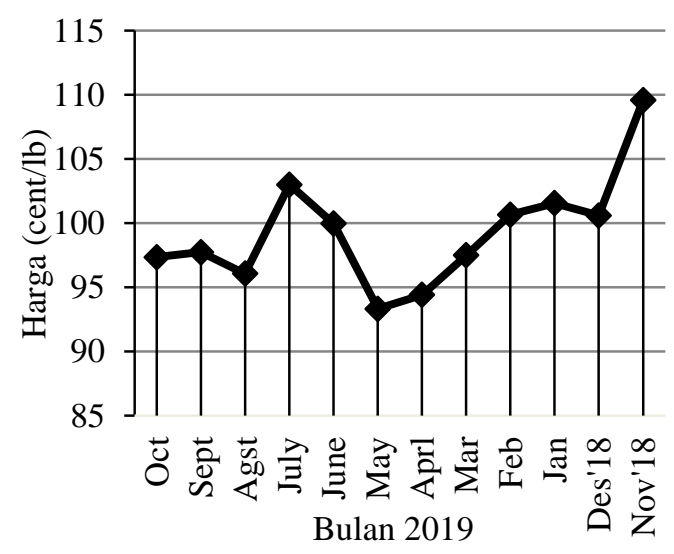

Gambar 2. Dinamika harga kopi dunia tahun 2019 (Sumber: Harga komposit, ICO)

Berdasarkan Gambar 2, terlihat bahwa harga rata-rata kopi arabika mengalami penurunan pada pertengahan tahun dan meningkat kembali pada saat akhir dan awal tahun. Hal ini disebabkan oleh umumnya panen raya kopi arabika di kawasan tropis, seperti di Indonesia dan Vietnam terjadi pada Bulan Oktober-Mei, dengan panen puncak pada Bulan JanuariMaret. Berdasarkan hal ini, Mayrowani (2013) menyatakan bahwa sangat penting untuk menentukan kebijakan teknologi pasca panen, dalam hal ini mengacu pada inovasi produk olahan terutama pada saat harga turun.
Tujuan dari penelitian ini adalah melakukan ekstraksi dan sintesis terhadap beberapa artikel ilmiah sistem produksi dan pengolahan untuk menentukan opsi penelitian yang akan datang (future work) dengan pendekatan berkelanjutan. Struktur artikel berdasarkan telaah kritis terhadap naskah (literatur review), sistematika pengklasifikasin berbasis topik, analisis konten dan sintesis serta penyusunan opsi penelitian ke depan (future work and needs).

Limitasi dari artikel ini adalah topik yang dikaji terbatas pada sistem produksi dan produk olahan kopi (downstream) serta beberapa titik kritis yang berpengaruh terhadap mutu produk yang dihasilkan. Pemaknaan (meaning) dari terminologi pengolahan dan produksi yang mengacu kepada kerangka sistem mengacu pada produk turunan komoditas kopi (downstream) untuk pengolahan, sedangkan produksi mengacu pada sistem produksi yang mencakup kegiatan produksi kopi dari hulu-hilir. Telaah (review) yang dilakukan pada kajian ini berbasis pendekatan berkelanjutan.

\section{METODE PENELITIAN}

\section{Tahapan Penelitian}

Sistematika penelitian ini dilaksanakan berdasarkan penelaahan (reviewed) dari beberapa artikel ilmiah (fokus) yang telah dipublikasi di jurnal (Gambar 3). Selain itu juga artikel yang bersifat teknis dan buku pegangan yang berkaitan dengan fokus kajian (handbook) untuk melengkapi telaah dan sintesis serta lingkup kegiatan ke depan (future work and needs).

\section{Sampel dan Metode Analisis}

Dalam penelitian ini artikel ilmiah yang dianalisis berjumlah 52 (Gambar 4), 95\% berasal dari jurnal ilmiah yang terindeks di Scopus, Thompson, Google Scholar, Copenicus, Academia.Edu. Researchgate, Ebsco, Portal Garuda, 
DOAJ dan Sinta-Kementrian Riset dan Teknologi (Kemenristek). 60\% merupakan terbitan 5 tahun terakhir (2015-2019).

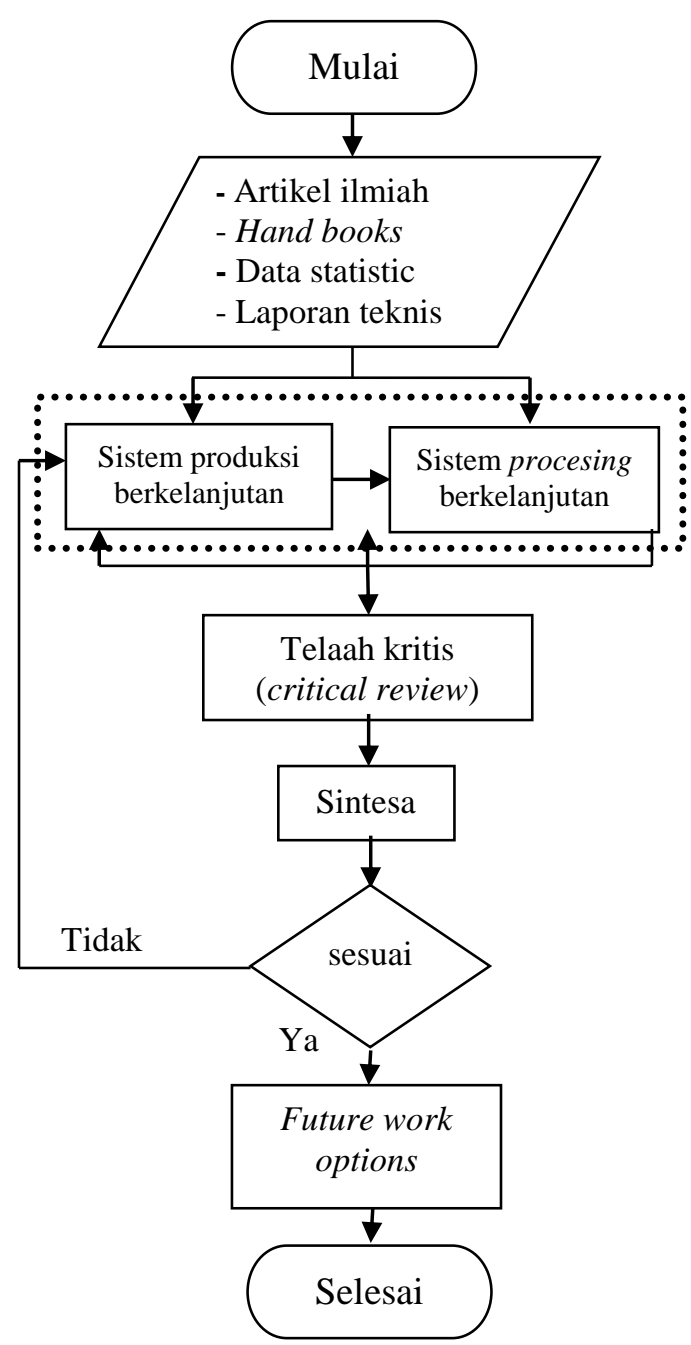

Gambar 3. Sistematika penelitian

Secara teknis, identifikasi artikel dilakukan melalui kata kunci (key words) yang akan dijadikan topik pada penelitian ini melalui portal beberapa publisher seperti Ebsco, Science Direct, Thomson, DOAJ, Academia-Edu, Researchgate, Sinta dan Google Cendikia (Scholar). Kata kunci yang digunakan antara lain coffee production, coffee processing, coffee development, susianability of coffee. Proses analisis dilakukan melalui sistem klaster terhadap artikel tersebut, yaitu berdasarkan sistem produksi dan pengolahan (processing) kopi secara berkelanjutan.

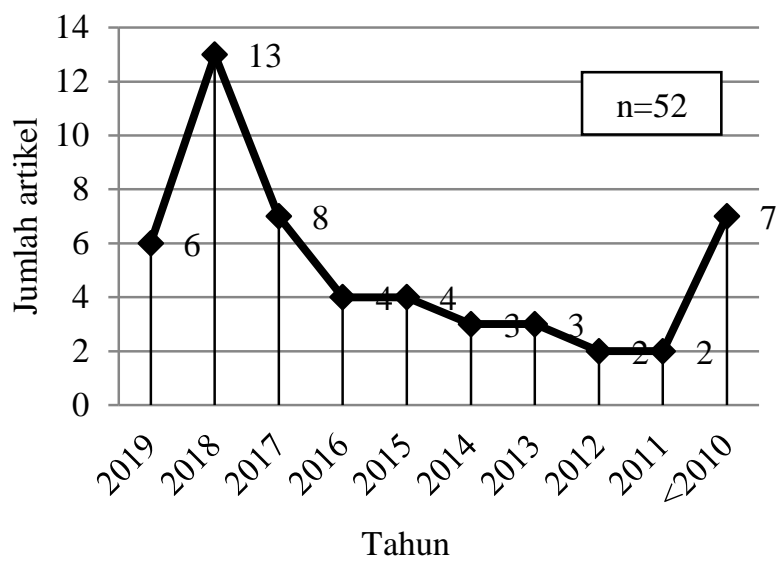

Gambar 4. Jumlah artikel ilmiah yang dianalisis

\section{HASIL DAN PEMBAHASAN}

\section{Konsep Berkelanjutan}

Dalam kajian ini, untuk mengetahui lebih dalam terhadap aspek berkelanjutan yang diaplikasikan pada sistem pengolahan dan produksi maka dilakukan kajian terhadap beberapa artikel. Dalam hal ini berkaitan dengan aspek/dimensi keberlanjutan yang diaplikasikan secara rinci ditunjukkan pada Tabel 1.

Dasar pemikiran dari konsep pembangunan berkelanjutan pada awalnya dipublikasi oleh World Commission on Environment and Development (WCED) pada tahun 1987 (Langhelle, 1999). Inti dari konsep tersebut Menurut Munasinghe (2010) adalah integrasi antara 3 dimensi utama, yaitu ekonomi, sosial dan lingkungan (ecology).

Konsep pembangunan berkelanjutan kemudian banyak diadopsi pada sistem pembangunan berbasis komoditi, misalnya pada kopi (Adam dan Ghaly, 2007). Demikian juga pada bidang keilmuan yang lain, seperti manajemen rantai pasok (Cuthbertson, 2011). 
Tabel 1. Beberapa artikel yang membahas dimensi berkelanjutan (ekonomi, sosial dan lingkungan)

\begin{tabular}{|c|c|c|}
\hline $\begin{array}{l}\text { Dimensi } \\
\text { berkelanjutan }\end{array}$ & Jurnal, tahun & Penulis \\
\hline Sosial & $\begin{array}{l}\text { Food Policy, } \\
2005\end{array}$ & $\begin{array}{l}\text { Giovannucci } \\
\text { dan Fonte }\end{array}$ \\
\hline $\begin{array}{l}\text { Ekonomi, sosial } \\
\text { dan lingkungan }\end{array}$ & $\begin{array}{l}\text { Cleaner } \\
\text { production, } \\
2007\end{array}$ & $\begin{array}{l}\text { Adam dan } \\
\text { Ghaly }\end{array}$ \\
\hline $\begin{array}{l}\text { Sosial dan } \\
\text { ekonomi }\end{array}$ & $\begin{array}{l}\text { Sustainability, } \\
2018\end{array}$ & $\begin{array}{l}\text { Cremaschi } \\
\text { et al. }\end{array}$ \\
\hline $\begin{array}{l}\text { Lingkungan } \\
\text { (global iklim) }\end{array}$ & $\begin{array}{l}\text { Jurnal Litbang } \\
\text { Pertanian, } 2017\end{array}$ & $\begin{array}{l}\text { Syakir dan } \\
\text { Surmaini }\end{array}$ \\
\hline Ekonomi, sosial & $\begin{array}{l}\text { Int. J. on Adv. } \\
\text { Sci. Eng. Infor. } \\
\text { Tech., } 2013\end{array}$ & Jaya et al. \\
\hline Lingkungan & $\begin{array}{l}\text { EEPSEA, } \\
\text { Policy Brief, } \\
2013\end{array}$ & Nuva et al. \\
\hline $\begin{array}{l}\text { Ekonomi, sosial } \\
\text { dan lingkungan }\end{array}$ & $\begin{array}{l}\text { Asian Coffee } \\
\text { Conf., } 2018\end{array}$ & Ram \\
\hline $\begin{array}{l}\text { Teknis produksi, } \\
\text { ekonomi }\end{array}$ & Plos-One, 2019 & Volsi et al. \\
\hline $\begin{array}{l}\text { Sistem produksi, } \\
\text { ekonomi dan } \\
\text { lingkungan }\end{array}$ & $\begin{array}{l}\text { J. of Natural } \\
\text { Sci. Research, } \\
2017\end{array}$ & Wolde et al. \\
\hline $\begin{array}{l}\text { Sosial } \\
\text { (partnerships) }\end{array}$ & IFAMA, 2017 & $\begin{array}{l}\text { Wijaya et } \\
\text { al.. }\end{array}$ \\
\hline $\begin{array}{l}\text { Ekonomi, sosial, } \\
\text { ekologi }\end{array}$ & $\begin{array}{l}\text { Agricultural } \\
\text { System, } 2008\end{array}$ & $\begin{array}{l}\text { Sydorovych } \\
\text { dan } \\
\text { Wossink }\end{array}$ \\
\hline $\begin{array}{l}\text { Ekonomi, sosial, } \\
\text { lingkungan }\end{array}$ & $\begin{array}{l}\text { Resourches, } \\
2017\end{array}$ & $\begin{array}{l}\text { Samper dan } \\
\text { Ruiz }\end{array}$ \\
\hline
\end{tabular}

\section{Sistem Produksi Berkelanjutan}

Dalam penelitian ini, pokok bahasan dimulai dari terminologi berkelanjutan. Menurut Gimenez et al. (2012) berkelanjutan merupakan integrasi dari aspek ekonomi, sosial dan lingkungan. Pada konteks sistem produksi pertanian, makna berkelanjutan berkaitan erat dengan nilai aggregate dari ketiga aspek tersebut (Sydrovych dan Wossink, 2008), demikian juga pada komoditas kopi (Giovanni dan Ponte, 2005).
Tabel 2. Beberapa artikel yang membahas aspek sistem produksi berkelanjutan

\begin{tabular}{|c|c|c|}
\hline Topik & Jurnal, tahun & Penulis \\
\hline $\begin{array}{l}\text { Sistem produksi } \\
\text { berkelanjutan } \\
\text { Vietnam }\end{array}$ & $\begin{array}{l}\text { Sustainability, } \\
2018\end{array}$ & $\begin{array}{l}\text { Cremaschi } \\
\text { et al. }\end{array}$ \\
\hline $\begin{array}{l}\text { Kaitan perubahan } \\
\text { iklim dengan } \\
\text { produksi dan } \\
\text { pengembangan }\end{array}$ & $\begin{array}{l}\text { Jurnal Litbang } \\
\text { Pertanian, } \\
2017\end{array}$ & $\begin{array}{l}\text { Syakir dan } \\
\text { Surmaini }\end{array}$ \\
\hline $\begin{array}{l}\text { Pemanfaatan kulit } \\
\text { kopi (review) }\end{array}$ & $\begin{array}{l}\text { Food Research } \\
\text { Interational, } \\
2014\end{array}$ & $\begin{array}{l}\text { Narita dan } \\
\text { Inouye }\end{array}$ \\
\hline $\begin{array}{l}\text { Sertifikasi } \\
\text { lingkungan dan } \\
\text { keberlanjutan kopi } \\
\text { Indonesia }\end{array}$ & $\begin{array}{l}\text { EEPSEA, } \\
\text { Policy Brief, } \\
2013\end{array}$ & Nuva et al. \\
\hline $\begin{array}{l}\text { Isu, konsep dan } \\
\text { aplikasi } \\
\text { keberlajutan }\end{array}$ & $\begin{array}{l}\text { Glocalism: } \\
\text { Journal of } \\
\text { Culture, } \\
\text { Politics and } \\
\text { Innovation, } \\
2018\end{array}$ & Rosen \\
\hline $\begin{array}{l}\text { Sistem produksi } \\
\text { kopi berkelanjutan }\end{array}$ & $\begin{array}{l}\text { Asian Coffee } \\
\text { Conference, } \\
2018\end{array}$ & Ram \\
\hline $\begin{array}{l}\text { Dinamika produksi } \\
\text { kopi Brazil }\end{array}$ & $\begin{array}{l}\text { Plos-One, } \\
2018\end{array}$ & Volsi et al. \\
\hline $\begin{array}{l}\text { Risiko dan manfaat } \\
\text { mengkonsumsi } \\
\text { kopi }\end{array}$ & $\begin{array}{l}\text { Medical and } \\
\text { Aromatic } \\
\text { Plants, } 2017\end{array}$ & Wachano \\
\hline $\begin{array}{l}\text { Sistem produksi } \\
\text { kopi, Ethiopia } \\
\text { (review) }\end{array}$ & $\begin{array}{l}\text { Journal of } \\
\text { Natural } \\
\text { Sciences } \\
\text { Research, } \\
2017\end{array}$ & $\begin{array}{l}\text { Wolde et } \\
\text { al. }\end{array}$ \\
\hline $\begin{array}{l}\text { Model partnership } \\
\text { sistem produksi } \\
\text { kopi Indonesia }\end{array}$ & IFAMA, 2017 & $\begin{array}{l}\text { Wijaya et } \\
\text { al.. }\end{array}$ \\
\hline $\begin{array}{l}\text { Pemahaman } \\
\text { pertanian } \\
\text { berkelanjutan }\end{array}$ & $\begin{array}{l}\text { Agricultural } \\
\text { System, } 2008\end{array}$ & $\begin{array}{l}\text { Sydorovych } \\
\text { dan } \\
\text { Wossink }\end{array}$ \\
\hline
\end{tabular}

\section{Sistem Pengolahan Berkelanjutan}

(Processing)

Dalam artikel ini sistem pengolahan, dalam hal ini termasuk produk turunan (downstream) berkelanjutan difokuskan pada beberapa hal penting yang mempengaruhi mutu produk kopi olahan 
yang dihasilkan. Menurut Clarke (2001) dan Oliviera et al. (2018), bahwa yang mempengaruhi mutu dari kopi (brewed) mencakup kultivar, blend, proses produksi dan penyimpanan. Secara detail, proses mencakup sejak biji kopi (cherry) dipanen sampai dengan kopi biji (green bean) siap diolah, dipasarkan atau disimpan (Tabel 3). Pada sisi yang lain, juga berkembangan pesat produk turunan berupa minuman

Tabel 3. Beberapa artikel yang membahas aspek pengolahan yang berkaitan dengan mutu produk kopi (brewed) dan produk

\begin{tabular}{lll}
\hline Topik & Jurnal, tahun & Penulis \\
\hline Deteksi adulterasi pada biji kopi (roasted) & Int. J. Food Science and Technology, & Song et al.
\end{tabular}

Shelf-life and sensory of cold-brew

Mutu sangrai (roasting)

Mutu sangrai (roasting)

Karaktersisasi produk cold-brew

Evaluasi aroma kopi (brewed)

Proses sangrai

Atribut sensori cold-brew

Konten kafein dan klorogenik cold-brew

Dampak fermentasi terhadap mutu

Level poliphenol dan kafein berdasarkan varietas

Penerimaan konsumen terhadap cold-brew

Perubahan mutu sensori selama penyimpanan

Pengaruh fermentasi terhaap mutu kopi biji

Optimasi penyangraian kopi robusta

Kualitas biji kopi arabika berdasarkan ketinggian

Analisis sensori kopi robusta

Kafein pada minuman campuran kopi dan kakao

Aspek yang mempengaruhi mutu kopi

Teknik pengeringan kopi

Pengolahan dan Pengeringan kopi

Aktivitas antioksidan dan keasaman cold-brew

Dampak perbedaan suhu dan waktu peyangraian (review)

Pengaruh penyangraian terhadap mutu kopi Ethiopia

Aspek teknis cupping test
Int. Proceeding of Sustainable Functional Foods \& Nutraceuticals, 2018

Journal of Applied Science and Agriculture, 2015

Food Science and Quality Management, 2016

J. Sci. Food Agri, 2017

Food Sci. Technology, 2011

Pelita Perkebunan, 2018

Pelita Perkebunan, 2019

Scientific Report, 2017

J. Food Quality, 2019

Food Chemistry, 2011

Food, 2019

Food Science and Nutrition, 2013

Journal of Food Quality, 2018

Food Quality and Preference, 2001

Pelita Perkebunan, 2016

Journal of Agricultural Studies, 2016

Journal of Innovative Research in Engineering and Science, 2012

Journal of Food Quality (editorial)

Food Science and Nutrition, 2019

International Journal of Engineering Research \& Technology, 2014

Scientific Report, 2018

Tropical Agriculture Science, 2016

Journal of Nutritional Ecology and

Food Research, 2015

Coffee Industry Board, 2008
Asiah et al.

Aliah et al.

Ameyu

Angeloni et al.

Bhumiratana et al.

Darmawan et al.

Dwiranti et al.

Fuller dan Rao

Haile dan Kang

Hecimovic et al.

Heo et al.

Kreuml et al.

Kwak et al.

Mendes et al.

Nugroho et al.

Ngugi dan Aluka

Ogah dan Obebe

Oliviera et al.

Phitakwinai et al.

Ghosh dan

Venkatachalapathy

Rao dan Fuller

Shan et al.

Tadesse et al.

Willis 
(beverages) berbahan baku kopi ataupun yang dicampur dengan bahan lain, misalnya coklat (Kwak et al., 2015), demikian juga dengan inovasi minuman ringan kopi cold-brew (Lane et al., 2017).

Berdasarkan aspek pengolahan, saat ini sudah terdapat inovasi produk turunan berbasis kopi dengan campuran komoditas lain, misalnya coklat (Ogah dan Ogebe, 2012). Selain itu seiring dengan berjalannya waktu, berkembang juga beberapa produk turunan dari komoditas kopi, misalnya minuman ringan (beverages) cold-brew (Rao dan Fuller, 2018; Aisah et al., 2018; Dwiranti et al., 2019; Hao et al., 2019). Selain itu upaya peningkatan mutu produk kopi masih menjadi hal penting, terutama yang berkaitan dengan pengaruh suhu dan waktu pada saat penyangraian (Mendes et al., 2001; Tadesse et al., 2015; Aliah et al., 2015; Shan et al., 2016). Pada sisi yang lain, juga penting untuk memperhatikan aspek lain yang berpengaruh pada mutu, misalnya fermentasi (Kwak et al., 2018; Haile dan Kang, 2019), aspek penyimpanan pada kopi (Kruemel et al., 2013), pengeringan biji kopi (Ghosh dan Venkatachalapathy, 2014; Phitakwinai et al., 2019).

Saat ini telah berkembang beberapa kegiatan (events) yang berkaitan dengan evaluasi sensori (Kreuml et al., 2013; Dwiranti et al., 2019; Hao et al., 2019). Hal terpenting bagi yang tertarik menjadi penguji (tester) adalah atribut dan teknis pelaksanaan cupping-test (Willis, 2008).

Secara keseluruhan pengembangan komoditas kopi saat ini harus memperhatikan aspek keberlanjutan (huluhilir), proses sertifikasi tidak hanya pada tataran manajerial tetapi harus diimplemantasikan sampai pada petani, terutama pada nilai premium (pengembalian) penjualan oleh eksportir. Tindak lanjut dari hal ini adalah sistem penelusuran (traceability) menjadi sangat penting sebagai dasar ketepatan pengembalian nilai premium tersebut (autentifikasi). Demikian juga dengan perkembangan produk turunan baru dari komoditas kopi ataupun campuran dengan komoditas lain, seperti kakao juga harus memperhatikan aspek keberlanjutan, agar nilai tambah produk jauh lebih meningkat.

\section{KESIMPULAN}

Pengembangan komoditas kopi harus memperhatikan aspek keberlanjutan yaitu ekonomi, sosial dan lingkungan. Hal ini berkaitan erat dengan meningkatnya permintaan kopi, terutama kopi arabika akibat dari perubahan gaya hidup, sedangkan pada sisi yang terdapat tantangan pada sistem produksi, salah satunya akibat pemanasan global. Demikian juga pada aspek pengolahan dan inovasi pada produk turunan.

\section{SINTESA}

Berdasarkan Tabel 1, 2 dan 3 terlihat bahwa fokus utama pengembangan komoditas kopi, baik itu jenis arabika maupun robusta lebih mengarah pada pendekatan berkelanjutan. Pada sistem produksi, jelas terlihat bahwa pemberlakuan beberapa sistem sertifikasi mengarah pada pengembagan kopi secara berkelanjutan (Nuva et al., 2013). Bahkan secara spesifik (Giovanucci dan Ponte, 2005) membahas aspek sosial. Demikian juga dengan hal eco-labeling dan pemanfaatan beberapa hasil samping (byproduct) kopi menjadi hasil olahan terbaru (Narita dan Inuoye, 2014).

\section{FUTURE WORK}

Sangat penting untuk melakukan kajian lebih lanjut terhadap produk turunan kopi, misalnya cold-brew dan minuman ringan (beverages) campuran kopi dengan produk lain, misalnya kopi terutama dari aspek mutu dan khusus bagi negara muslim adalah sistem serfikasi halal. Demikian juga dengan kajian yang mencakup susbtansi dari pembangunan berkelanjutan komoditas kopi, terutama yang mencakup perubahan iklim, 
penggelolaan sosial-konflik dan distribusi keuntungan yang berkeadilan.

\section{DAFTAR PUSTAKA}

Adam, M., Ghaly, A.E. 2007. Maximizing sustainability of the costarican coffee industry. Journal of Cleaner Production, 15: 1716-1729.

Aliah, A.M.N., Edzuan, A.M.F., Diana, A.M.N. 2015. A Review of quality coffee roasting degree evaluation. Journal of Applied Science and Agriculture, 10 (7): 18-23.

Ameyu, M.A. 2016. Physical quality analysis of roasted arabica coffee beans subjected to different harvesting and postharvest processing methods in Eastern Ethiopia. Food Science and Quality Management, 57: $1-9$.

Asiah, N., Dewi, E.C., Astuti, R.M. 2018. Shelf Life Prediction and Sensory Attributes of Cold Brew Cibulao Arabica Coffee During Storage. Proceeding of Workshop \& Conference, Jakarta 27-28 March 2018.

Astuti, E.S., Offermans A., Kemp R., Corver R. 2015. The impact of coffee certification on the economic performance of indonesian actors. Asian Journal of Agriculture and Development, 12 (2): 1-14.

Angeloni, G., Guerrini, L., Masella, P., Innocenti, M., Bellumori, M., Parenti, A. 2017. Characterization and comparison of cold brew and cold drip coffee extraction methods. J. Sci. Food Agric.

Bhumiratana, N., Adhikari, K., Chambers, E. 2011. Evolution of sensory aroma attributes from coffee beans to brewed coffee, Food Sci. Technology, 4: 21852192.

Clarke, R.J. 2001. Instant Coffee and Processing, Coffee Recent Development (edited Clarke dan Vitzhnum). Blackwell Science Ltd, Paris.

Cowan, B. 2005. The Social Life of Coffee, the emergence of British Coffee House. websrv-cluster-ip8.its.yale.edu.
Cremaschi, G., D., van Evert F.K., Jansen D. M., Meuwissen M. P. M., Lansink A. G. J. M. 2018. Assessing the sustainability performance of coffee farms in Vietnam: A social profit inefficiency approach. Sustainability, 10 (4277): 1-23.

Cuthbertson, R. 2011. The need for sustainable supply chain management di dalam Sustainable Supply Chain Management: Practical Ideas for Moving Towards Best Practice. Springer-Verlag Berlin Heidelberg.

Dwiranti, N., S., Ardiansyah, Asiah., N. 2019. Sensory attributes of cold brew coffee products at various resting time after roasting process. Pelita Perkebunan, 35 (1): 42-50.

Farah, A. 2011. Coffee Constituents. Coffee Emerging Health Effect and Disease Prevention. Editor YF Chu. IFT Press, John Wiley and Sons, New Delhi, India.

Fuller, M., dan Rao, N.Z. 2017. The effect of time, roasting temperature, and grind size on caffeine and chlorogenic acid concentrations in cold brew coffee. Scientific Report, 7 (17997): 1-9.

Darmawan, A., Cahyo, F., Widyotomo., S. 2018. Determining optimum point of robusta coffee bean roasting process for taste consistency. Pelita Perkebunan, 34 (1): 59-65.

Gimenez, C., Sierra, V., Rodon, J. 2012. Sustaineble operation: Their impact on the triple bottom line. Int. Journal Production Economic, 140: 149-159.

Giovannucci, D., dan Ponte S. 2005. Standart as a new form of social contract: Sustainability initiative for coffee industry. Food Policy, 30: 284-301.

Ghosh, P., dan Venkatachalapathy, N. 2014. Processing and drying of coffee, A review. International Journal of Engineering Research \& Technology, 3 (12): 784-794.

Haile, M., and Kang, W., H. 2019. The role of microbes in coffee fermentation and their impact on coffee quality. Journal of Food Quality, Article ID 4836709: 1-6. 
Hatzold, T. 2011. Introduction, Coffee Emerging Health Effect and Disease Prevention. Editor YF Chu. IFT Press, John Wiley and Sons, New Delhi, India.

Hecimovic, I., Belscak-Ctinovic, A., Horzic, D., Komes, D. 2011. Comparative study of polyphenol and caffein in different coffee varieties affected by the degree roasting. Food Chemistry, 129: 991-1000.

Heo, J., Choi, K., E., Wang, S., Adhikari, K., Lee., J. 2019. Cold brew coffee: Consumer acceptability and characterization using the check-all-thatapply (CATA) Method. Foods, 8 (34): 114.

Ho, T., Wilson C., Hoang V-N., Nguyen T., T. 2018. Eco-efficiency analysis of sustainability-certified coffee production in Vietnam. Journal of Cleaner Production, Accepted Manuscript.

International Coffee Organization [ICO]. 2019. Total Production Coffee by Exporting Countries. [Diakses 18 Nopember 2019].

Jaya, R., Machfud, Raharja S, Marimin. 2013. Sustainability analysis for gayo coffee supply chain. International Journal on Advanced Science Engineering Information Technology, 3 (2): 24-28.

Kreuml, M., T., L., Majchrzak, D., Ploederl, B., Koening, J. 2013. Changes in sensory quality characteristics of coffee during storage. Food Science \& Nutrition, 1-6. Wiley Int.

Krishnan, S. 2017. Sustainable Coffee Production. Oxford Research Encyclopedia of Environmental Science. Oxford University Press, USA.

Kwak, H., S., Kim., M., Jeong, Y. 2015. Developing Water-extracted cacao-coffee beverage: Effects of temperature and time on cacao roasting and the beverage acceptability. CYTA Journal of Food, 14 (2): 248-258

Kwak, H., S., Jeong., Y., Kim, M. 2018. Effect of yeast fermentation of green coffee beans on antioxidant activity and consumer acceptability. Journal of Food Quality, Article ID 5967130: 1-8.
Lane, S., Palmer, J., Christie, B., R., Ehlting, L., Le, C., H. 2017. Can cold brew coffee be convenient? A pilot study for caffeine content in cold brew coffee concentrate using high performance liquid chromatography. The Arbutus Review, 8 (1): 15-23.

Langhelle, O. 1999. Sustainable Development: Exploring the Ethics of Our Common Future. International Political Science Review, 20 (2): 129-149.

Mayrowani, H. 2013. Kebijakan penyediaan teknologi pasca panen kopi dan masalah pengembanganya. Forum Penelitian Agro Ekonomi, 31 (1): 31-49.

Mendes, L., C., Menezes, H., C., Aparecida, M., da Silva, A., P. 2001. Optimization of the roasting of robusta coffee (C. canephora conillon) using acceptability tests and RSM. Food Quality and Preference, 12: 153-162.

Munasinghe, M. 2010. Sustainomics framework and practical application. MIND Press. Srilanka: Munasinghe Institute for Development.

Narita, Y., Inouye K. 2014. Review on Utilization and Composition of Coffee Silverskin. Food Research International, Article in Press.

Ngugi, K., Aluka, P. 2016. Sensory and organoleptic cup attributes of robusta coffee (Coffea canephora Pierre ex A. Froehner). Journal of Agricultural Studies, 4 (1): 1-16.

Nugroho, D., Basunanda, P., Mw, S. 2016. Physical bean quality of arabica coffee (Coffea arabica) at high and medium altitude. Pelita Perkebunan, 32 (3): 1-11.

Nuva, Yusif, Kuniawati, N., Hanna. 2013. Eco-labelling offers a sustainable future for indonesian coffee. EEPSEA Policy Brief, 2013-PB8.

Ogah, C.O., and Obebe, O.T. 2012. Caffeine content of cocoa and coffee beverages in Lagos, Nigeria. Journal of Innovative Research in Engineering and Sciences 3 (1): 404-141. 
Oliviera, G.H., Oliviera, A.P.L.R., Botelho, B.M., Treto, P.C., Botelho, S.C.C. 2018. Coffee quality: Cultivars, blends, processing, and storage impact [editorial]. Journal of Food Quality.

Phitakwinai, S., Thepa, S., Nilnont, W. 2019. Thin-layer drying of parchment arabica coffee by controlling temperature and relative humidity. Food Science and Nutrition, 1-11.

Ram, A.S. 2018. Sustaining coffee production: Present and future. Prosiding Asian Coffee Association Annual Conference, Mangshi, China 11-12 November.

Rao, N.Z., dan Fuller, M. 2018. Acidity and antioxidant activity of cold brew coffee. Scientific Report, 8 (16030): 1-9.

Rosen, M.A. 2018. Issues, concepts and applications for sustainability. Glocalism, 3: $1-21$.

Samper, L.F., dan Quiñones-Ruiz, X.F. 2017. Towards a Balanced Sustainability Vision for the Coffee Industry. Resources, 6 (17) : 1-28.

Shan, O.E., Zzaman, W., Yang, T.A. 2016. Impact of different temperature-time profiles during superheated steam roasting on some physical changes of robusta coffee. Tropical Agriculture Science, 39 (3): 311-320.

Song, H.Y., Jang, H.W., Debnath, T., Lee, KG. 2019. Analytical method to detect adulteration of ground roasted coffee. Int. Journal Food Science and Technology, 54: 256-262.

Syakir, M., dan Surmaini, E. 2017. Perubahan iklim dalam konteks sistem produksi dan pengembangan kopi di Indonesia. Jurnal Litbang Pertanian, 36 (2): 77-99.

Sydorovych, O., Wossink, O. 2008. The meaning of agricultural sustainability: Evidence from a conjoint choice survey. Agricultural System, 98: 10-20.

Tadesse, T., Jemal, Y., Abebe, H. 2015. Effect of green coffee processing methods and roasting temperatures on physical and cup quality of Sidama Coffee, Southern Ethiopia. Journal of Nutritional Ecology and Food Research, 3: 1-7.
Wachano, H.L. 2017. Review on health benefit and risk of coffee consumption. Medical and Aromatic Plants, 6 (4): 1-12.

Willis, H. 2008. Sensory Evaluation of Coffee: Cuptesting. Coffee Industry Board (CIB).

Wijaya, A., Glasbergen P., Mawardi S. 2017. The mediated partnership model for sustainable coffee production: experiences from Indonesia. International Food and Agribusiness Management Review, Article-in Press.

Wolde, Z., Tefera, A., Yared, S., Gezahagn, T., Tadesse, T. 2017. A Review on coffee farming, production potential and constraints in Gedeo Zone, Southern Ethiopia. Journal of Natural Sciences Research, 7 (23): 1-9.

Volsi, B., Telles T.S., Caldarelli, C.E., and Camara, M.R.G. 2019. The dynamics of coffee production in Brazil. PLOS ONE, 14 (7): 1-15. 